\title{
BMJ Open Ultrasound-guided bilateral pudendal nerve blocks of nulliparous women with epidural labour analgesia in the second stage of labour: a randomised, double-blind, controlled trial
}

Jialing Xu, ${ }^{1}$ Riyong Zhou, ${ }^{2}$ Weijue Su, ${ }^{3}$ Shi Wang, ${ }^{2}$ Yun Xia, ${ }^{4}$ Thomas Papadimos, ${ }^{4}$ Junzhao Zhao (D), ${ }^{3}$ Xuzhong $\mathrm{Xu}^{2}$

To cite: Xu J, Zhou R, Su W, et al. Ultrasound-guided bilateral pudendal nerve blocks of nulliparous women with epidural labour analgesia in the second stage of labour: a randomised, double-blind, controlled trial. BMJ Open 2020;10:e035887. doi:10.1136/ bmjopen-2019-035887

- Prepublication history for this paper is available online. To view these files, please visit the journal online (http://dx.doi. org/10.1136/bmjopen-2019035887).

$\mathrm{JX}$ and $\mathrm{RZ}$ are joint first authors.

Received 20 November 2019

Revised 17 July 2020

Accepted 21 July 2020

Check for updates

(C) Author(s) (or their employer(s)) 2020. Re-use permitted under CC BY-NC. No commercial re-use. See rights and permissions. Published by BMJ.

For numbered affiliations see end of article.

Correspondence to

Dr Junzhao Zhao;

z.joyce08@163.com and

Dr Xuzhong Xu;

xuzhong@263.net

\section{ABSTRACT}

Objective To explore whether an ultrasound-guided pudendal nerve block (PNB) could decrease anaesthetic use, thereby shortening the length of the second stage of labour in women undergoing epidural analgesia.

Design Prospective, single-centre, randomised, doubleblind, controlled trial.

Setting An obstetric centre in a general hospital in China. Participants 72 nulliparous women were randomised, and 71 women completed the study.

Intervention An ultrasound-guided bilateral PNB was administered to all study participants; the PNB group were given $0.25 \%$ ropivacaine $10 \mathrm{~mL}$, while the control group were given $10 \mathrm{~mL}$ saline.

Main outcome measure The primary outcome measure was the duration of the second stage of labour. Secondary outcomes included additional bolus administration, total hourly bupivacaine consumption, difference in thickness between the contracted and relaxed rectus abdominis muscle before (DRAM1) and 30 min after (DRAM2) PNB, urge to defecate, maternal cooperation, preservation of the lower limb motor function, tightness of the perineum, and Numeric Rating Scale (NRS) score for pain.

Results The duration of the second stage of labour was shorter in the PNB group than in the control group (difference of $33.8 \mathrm{~min}(95 \% \mathrm{Cl} 15.6$ to 52.0$), \mathrm{p}<0.001)$. Additional bolus administration and total hourly bupivacaine consumption were lower in the PNB group than in the control group $(p<0.001)$. DRAM2 was greater $(p<0.001)$, rate of parturient women with the urge to defecate was higher $(p=0.014)$, maternal cooperation was superior $(p=0.002)$, and lower limb motor function preservation was greater $(p=0.004)$ in the PNB group relative to the control group. Tightness of the perineum was eliminated from the results due to the inconsistent application of the criteria by the nursing staff. There was no significant difference in NRS scores between the groups.

Conclusions Nulliparous women with epidural analgesia who received an ultrasound-guided bilateral PNB may reduce their need for bupivacaine and consequently shorten the length of the second stage of labour, therein indicating that a bilateral PNB may serve as an additional effective adjunct method of labour analgesia.

\section{Strengths and limitations of this study}

- This was a prospective, randomised, double-blind, controlled trial designed to observe the efficacy of ultrasound-guided bilateral pudendal nerve blocks as an additional analgesia strategy during labour.

- The study solution was injected directly into the surroundings of the pudendal nerve under ultrasound guidance, ensuring safe and effective analgesia.

- This was a single-centre clinical trial design which may limit the generalisation of the conclusions.

- Some secondary outcomes were post-hoc and may pose a risk of bias.

Trial registration number ChiCTR-IOR-16009121.

\section{INTRODUCTION}

Epidural analgesia is one of the most widely used procedures for pain relief during childbirth. There is evidence that epidural analgesia will lengthen the second stage of labour. Shmueli et $a l^{1}$ retrospectively demonstrated that the use of epidural analgesia extended the second stage of labour by $95 \mathrm{~min}$ (193 vs 98 min of the 95 th percentile for epidural vs no epidural, respectively). Cheng et $a l^{2}$ found that epidural analgesia was associated with more than a 2-hour (the difference of the 95th percentile threshold) prolongation of the second stage of labour for both nulliparous and multiparous women.

It is important to note that $64.6 \%$ of women with sufficient analgesia initially had a subsequent deterioration in their Visual Analogue Pain Scale score. ${ }^{3}$ Despite the presence of lowthoracic/high-lumbar analgesia in the first stage of labour, sacral analgesia is required in the second stage of labour. ${ }^{4}$ It is common to administer additional epidural doses to supplement insufficient analgesia during 
the second stage of labour. However, such supplemental dosing may increase motor blockade of the lower limbs/ torso, thereby reducing the effectiveness of labour. ${ }^{56}$

A pudendal nerve block (PNB) is an effective pain relief method in the late second stage of labour during vaginal birth, providing analgesia to the vulva and the anus. ${ }^{7}$ Tafeen $e t a l^{8}$ demonstrated a method of administering combined continuous paracervical and PNB anaesthesia during labour thereby markedly reducing the dosage of systemic analgesic drugs required and avoiding adverse events inherent in other forms of conduction anaesthesia.

In view of this, we hypothesised that performing bilateral PNB would shorten the duration of the second stage of labour secondary to the reduced need for supplemental dosing of the epidural and preservation of pelvic splanchnic nerve function (which is important to vaginal delivery). ${ }^{9}$ We designed a prospective, double-blind, randomised clinical trial where the primary outcome was the duration of the second stage of labour. Secondary outcomes included the additional need for bupivacaine, total hourly bupivacaine consumption, difference in thickness between the contracted and relaxed rectus abdominis muscle (DRAM) before and $30 \mathrm{~min}$ after PNB, urge to defecate, maternal cooperation during labour, and preservation of lower limb motor function.

\section{METHODS}

\section{Study design}

The trial was registered prior to patient enrolment in the Chinese Clinical Trial Registry (principal investigators: JX, RZ and XX; date of registration: 30 August 2016). This manuscript adheres to the applicable Consolidated Standards of Reporting Trials guidelines. Between 1 September 2016 and 31 January 2017, a total of 1681 women presented for labour and delivery at The First Affiliated Hospital of Wenzhou Medical University. The women who met the inclusion criteria were informed of the study protocol and their rights when they reached $6 \mathrm{~cm}$ of cervical dilation. Written informed consent was obtained from the subjects at this time. The trial was ended when 72 women were randomised. Inclusion criteria were nulliparous women 20-35 years who were between 36 and 42 weeks of gestation and requested epidural labour analgesia, American Society of Anesthesiologists physical status II, normal coagulation function and head presentation of the fetus, and had received effective epidural analgesia (Numeric Rating Scale (NRS) for pain $<4$ ) during the first stage of labour. Exclusion criteria were any contraindication to regional anaesthesia or history of sensitivity or allergy to local anaesthetic; specific diseases of pregnancy, including hypertensive disorders complicating pregnancy, intrahepatic cholestasis of pregnancy, gestational diabetes mellitus and hyperemesis gravidarum; and pregnancy with diseases of other systems, including cardiovascular disease, suspicion of fetal malformations or intrauterine growth restriction, multiple pregnancy, abnormal placenta or membrane, abnormal amniotic fluid, or an umbilical cord abnormality.

\section{Patient and public involvement}

Neither patients nor the public were involved in the study design, conduct, reporting or dissemination of the research plan.

\section{Randomisation and blinding}

In this study, a single investigator used SPSS V.22.0 software to randomly generate numbers from 1 to 72 for the cases/subjects. The result was placed into an opaque envelope with the same serial number (grouping conditions were 1:1). This investigator was then recused from further involvement in the study. The 72 envelopes were submitted to the obstetrics clinic and randomisation was performed when a patient's cervix dilated to $7-8 \mathrm{~cm}$. The 72 participants were randomised into two groups, the PNB group and the control group, with 36 subjects each.

The envelopes remained sealed until performance of PNB. The research nurse unsealed the envelope to prepare the stated solution and did not participate in the study subsequently, and was the only unblinded person aware of the study group allocations. All PNBs were performed by an attending anaesthetist. A second anaesthetist was responsible for recording the NRS score during the second stage of labour and the documentation of other outcomes.

\section{Intervention}

\section{Epidural analgesia during the first stage of labour}

After epidural catheter placement, $3 \mathrm{~mL}$ of $1.5 \%$ lidocaine with epinephrine $(1: 200000)$ was administered to ensure the catheter was in the correct position. Then an initial bolus of $0.067 \%$ bupivacaine with $2 \mu \mathrm{g} / \mathrm{mL}$ fentanyl $20 \mathrm{~mL}$ was administered, followed by an infusion of the same solution at $12-15 \mathrm{~mL} /$ hour. The epidural infusion continued throughout labour. Pain was evaluated using $\mathrm{NRS}^{10}$; 0 represented 'no pain' and 10 represented 'the worst imaginable pain'. A score of $\geq 4$ was regarded as insufficient analgesia. An additional $10 \mathrm{~mL}$ of the local anaesthetic solution was given if an NRS score of $\geq 4$ occurred at any time during the first stage of labour. If required, $10-12 \mathrm{~mL}$ of $0.125 \%$ bupivacaine was used to ensure the NRS score was $<4$.

\section{Ultrasound-guided bilateral PNB}

The PNB technique was performed when the cervix was dilated to $9 \mathrm{~cm}$. The participant was placed in the right lateral decubitus position. The sites for injection/epidural placement were prepared in a sterile fashion. An attending anaesthetist was positioned behind the subject and used a 5-2 MHz ultrasound probe (SonoSite X-Porte, SonoSite, Bothell, Washington, USA) to identify the appropriate anatomy. The probe was placed below the ischial spine, perpendicular to the skin. The placement and orientation of the probe, in its initial position, were along the line connecting the greater trochanter and the posterior superior iliac spine. Thereafter, the probe was shifted in 


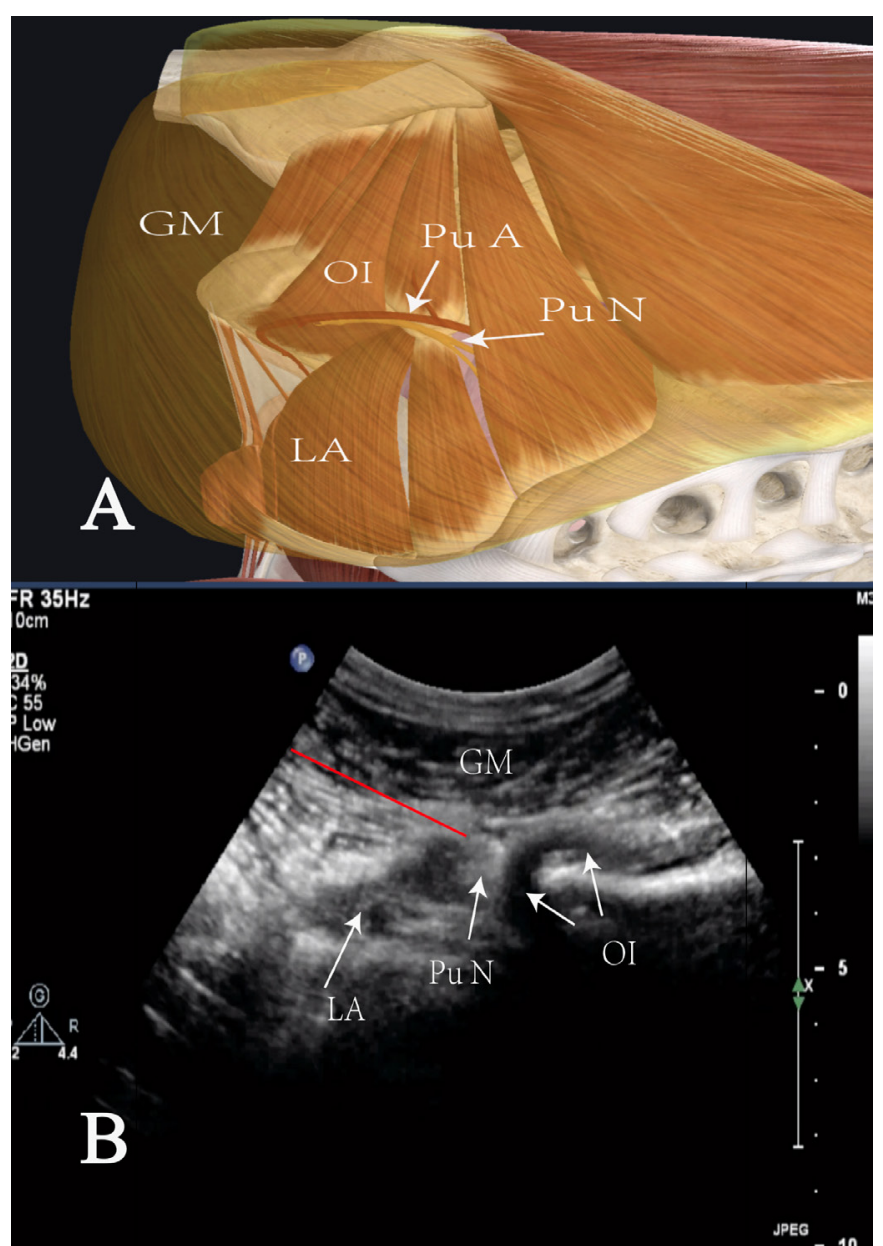

Figure 1 Neuroanatomy and ultrasound imaging of the hips during pudendal nerve block. (A) Topography of the pudendal artery (Pu A) and pudendal nerve (Pu N); and (B) ultrasound depiction of the pudendal nerve. The pudendal nerve is round and hyperechoic. It is located between the gluteus maximus (GM) and the levator ani (LA). Also, note the obturator internus (OI). The red line denotes the needle.

a parallel manner inferomedially. ${ }^{11}$ The pudendal nerve, a round hyperechoic structure located between the gluteus maximus and the levator ani muscles, medial to the obturator internus, was then identified (figure 1A,B). An $80 \mathrm{~mm}, 22 \mathrm{G}$, short bevel needle (Stimuplex D Plus, B Braun, Melsungen, Germany) was visualised and advanced from the medial to the lateral direction using an inplane technique until its point was positioned in the immediate vicinity of the pudendal nerve. After negative aspiration, $2 \mathrm{~mL}$ of saline was injected to ensure the fluid enveloped the pudendal nerve, and then a subsequent $10 \mathrm{~mL}$ of the study solution was injected. The contralateral side was blocked in the same manner. The participants in the PNB group were given $0.25 \%$ ropivacaine $10 \mathrm{~mL}$ on each side, while the participants in the control group were given $10 \mathrm{~mL}$ of saline.

After performance of the PNB technique, the NRS score was evaluated every $15 \mathrm{~min}$ until the end of the second stage of labour. If the score was $\geq 4,10 \mathrm{~mL}$ of $0.125 \%$ bupivacaine was injected and the infusion rate was increased by $4 \mathrm{~mL} /$ hour. If there was no improvement (NRS score remains $\geq 4$ ), the same process would be repeated with administration of another $8 \mathrm{~mL}$ of $0.25 \%$ bupivacaine and an increase in the infusion rate by another $4 \mathrm{~mL} /$ hour. Maternal oxygen saturation, heart rate, non-invasive blood pressure and fetal heart rate were monitored during labour.

\section{Outcome measures}

Demographic data of the parturient women included maternal age, height, weight and gestational age. The primary outcome was the duration of the second stage of labour, which was identified when the cervix dilated to $10 \mathrm{~cm}$, and ended with delivery of the neonate. Secondary outcomes included the additional administration of bupivacaine boluses, bupivacaine consumption, DRAM before and 30 min after PNB, urge to defecate, maternal cooperation, rate of preservation of lower limb motor function, tightness of the perineum, and NRS scores (a marker of analgesia) which showed the analgesic effect. Additional bupivacaine boluses and bupivacaine consumption were recorded by the anaesthetist as routine part of labour analgesia and defined as (1) the necessary additional boluses to treat an NRS score of $\geq 4$ during the second stage of labour and (2) the total hourly bupivacaine required during the second stage of labour, respectively. The thickness of the rectus abdominis muscle was evaluated by ultrasound with a $6-16 \mathrm{MHz}$ probe. The measurement method was as follows: a line connecting the pubic symphysis with the umbilicus (longitudinal) was drawn (as line 1), and then a vertical line (lateral) was drawn through the midpoint of line 1 (as line 2). The long axis of the probe was placed on the rectus abdominis to the right side of line 2 . When a contraction commenced, the thickest part of the rectus abdominis was identified and was marked with a dot. The investigator then placed the midpoint of the probe on the dot and drew the shape/outline of the probe. On the next contraction, the probe was placed on the graphic, thereby ensuring each measurement was taken in the same position. When the parturient woman felt the onset of a contraction, she was encouraged to hold her breath and push in order to simulate the act of defecation. At this point the ultrasound image was frozen and measurements were performed (during maternal rectus abdominis contraction and relaxation). The thickness of the rectus abdominis was measured, and the difference between the two states was recorded and reported as the DRAM (DRAM=contracted thickness-relaxed thickness). The DRAM measurement before the block was DRAM1, and the DRAM measurement at $30 \mathrm{~min}$ after the block was DRAM2. The labour nurses enquired of the nulliparous women if they could feel the urge to defecate during the second stage of labour and this was recorded as a yes or no. Maternal cooperation was judged by the labour nurse as good, moderate or poor. Documentation of 'good' indicated that the patient could cooperate well with the nurse, 'moderate' indicated that the patient could sometimes cooperate, and 'poor' indicated that 
the patient could not effectively cooperate with the nurse during labour. Routinely, the strength of the quadriceps was evaluated and recorded by the anaesthetist in order to determine lower limb function. Documentation of ' $4+$ ' indicated an ability to move against strong resistance. ${ }^{12}$ The tightness of the perineum was judged by the labour nurses as loose or tight. NRS scores were recorded and evaluated by an anaesthetist before the PNB and every 15 min after block placement until the end of the second stage of labour.

Additional data collected included the duration of the first and third stage of labour, blood loss, parturient women requiring oxytocin, mode of delivery, maternal satisfaction, postpartum length of stay, neonatal weight, and Apgar scores at 1 and $5 \mathrm{~min}$. The first stage was identified with onset of regular uterine contractions as reported to the obstetrician. Blood loss was recorded and entered into the hospital system by the labour nurses. Those requiring oxytocin during the second stage of labour were recorded by labour nurses. The mode of delivery, including vaginal, episiotomy, forceps-assisted and caesarean delivery, was recorded by labour nurses, as were neonatal weight and neonatal Apgar scores at 1 and $5 \mathrm{~min}$. On the first postpartum day, the patient was queried as to her level of satisfaction regarding pain relief during the second stage of labour; ' 1 ' indicated very unsatisfactory, ' 3 ' indicated somewhat satisfactory and ' 5 ' indicated very satisfactory. The postpartum length of stay was also documented.

It should be noted that some indicators have different names in the manuscript from those in the trial registry. The result of the analgesic effect in the trial registry was presented as the NRS score, and the thickness of the abdominal muscle was equal to the result of DRAM. Delivery outcome was equal to the mode of delivery, including episiotomy, forceps-assisted delivery and caesarean. Some indicators were post-hoc and have not been prespecified in the trial registry, including the additional injection times, bupivacaine consumption, urge to defecate, maternal cooperation, preservation of lower limb motor function, women with oxytocin, postpartum length of stay and neonatal weight. All these outcomes were obtained from obstetric records or anaesthetic records.

The PNB procedure was considered to have been successful when the pudendal nerve was found on ultrasound to be enveloped by the anaesthetic solution. The primary complications of PNB observed after block placement are local anaesthetic toxicity caused by intravascular injection, the occurrence of haematomas and nerve damage.

\section{Statistical analysis}

The sample size for this study was determined from prestudy data using Power Analysis and Sample Size (PASS V.11.0) software. In the prestudy period, there were five women in each group. The length of the second stage was $109.6 \pm 31.6 \mathrm{~min}$ in the control group and $87.6 \pm 17.9 \mathrm{~min}$ in the PNB group. A calculated sample size of 30 women in each group was required to provide a statistical power of 0.90 and type I error of 0.05 using two-sample t-test analysis in order to detect a difference of the same magnitude and assuming the same SD as in the pilot data. We enrolled 36 parturient women in each group to allow for possible dropouts or missing data.

Data were analysed using SAS V.9.4. Continuous variables were summarised using mean and SD or median with 25th and 75th percentiles (dependent on variable distribution). The normal distribution of data was assessed by the Shapiro-Wilk test. Categorical variables were presented using counts and percentages. Normally distributed data were analysed by two-sample t-test. Nonnormally distributed data and ranked data were analysed by the Mann-Whitney U test. Categorical data were compared using $\chi^{2}$ test. A two-sided $\mathrm{p}$ value $<0.05$ was considered statistically significant.

\section{RESULTS}

Between 1 September 2016 and 31 January 2017, a total of 1681 women presented for labour and delivery at The First Affiliated Hospital of Wenzhou Medical University; 216 women met the inclusion criteria for this study, 103 were consented and 72 were randomised. One was excluded from data collection due to irreversible prolonged fetal decelerations after randomisation requiring a caesarean section, but before the PNB (figure 2); 71 women completed the study. There were no significant differences in demographic data and intrapartum baseline between the PNB group and the control group (table 1).

The primary outcome, the duration of the second stage of labour, was shorter in the PNB group than in the control group ( $73 \pm 31 \mathrm{~min}$ vs $106 \pm 45 \mathrm{~min}$, difference of $33.8 \min (95 \%$ CI 15.6 to 52.0$), \mathrm{p}<0.001$ ).

As shown in table 2, the additional number of boluses required was significantly lower in the PNB group, and the total $\mathrm{mg}$ /hour consumption of bupivacaine during the second stage of labour was 6.7 (6.7-16.23) in the PNB group compared with 17.35 (15.45-21.55) in the control group $(\mathrm{p}<0.001)$. There was no significant difference observed with regard to DRAM1 between the two groups, while DRAM2 was significantly thicker in the PNB group relative to the control group $(\mathrm{p}<0.001$; table 2$)$. More women in the PNB group felt the urge to defecate in the second stage $(p=0.014$; table 2$)$. Similarly, maternal cooperation was better in the PNB group than in the control group ( $\mathrm{p}=0.002$; table 2$)$. The lower limb motor function was better preserved in the PNB group than in the control group $(\mathrm{p}=0.004$; table 2$)$. The result of perineum tightness was eliminated from the study due to the inconsistent application of the criteria by the labour nurses. There were no significant differences in NRS scores between the groups from 0 to 105 min during the second stage of labour (figure 3 ). The participants in the PNB group were more satisfied with their pain relief than those in the control group ( $\mathrm{p}=0.023$; table 3$)$. 


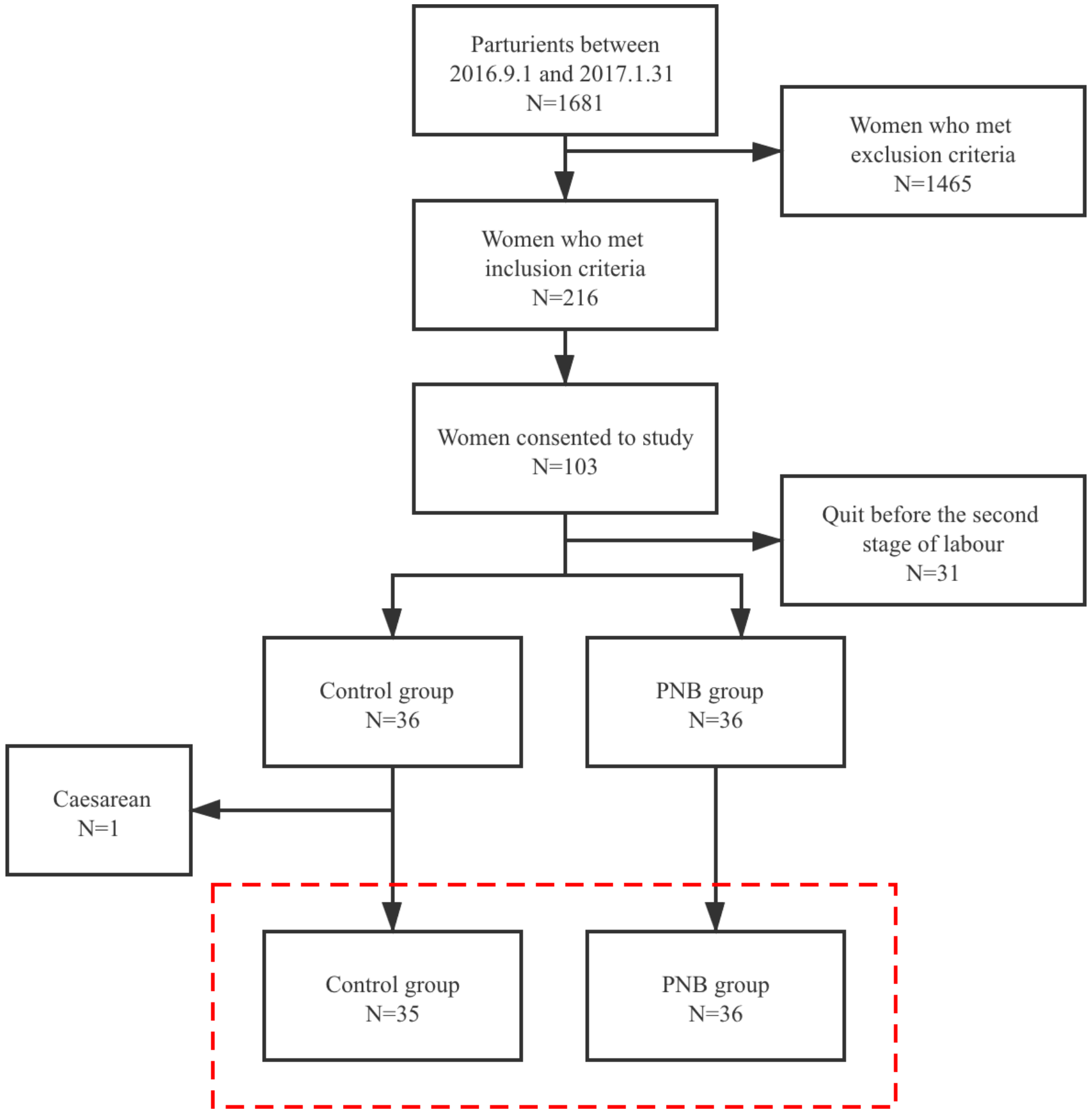

Figure 2 Flow diagram of study participants. PNB, pudendal nerve block.

\begin{tabular}{llll}
\hline Table 1 & Demographic data and intrapartum baseline \\
\hline & $\begin{array}{l}\text { Control group } \\
(\mathbf{n}=\mathbf{3 6})\end{array}$ & $\begin{array}{l}\text { PNB group } \\
(\mathbf{n}=\mathbf{3 6})\end{array}$ & P value \\
\hline Maternal age (years) & $27.8 \pm 3.4$ & $26.5 \pm 2.7$ & 0.08 \\
Maternal height $(\mathrm{cm})$ & $158.9 \pm 4.8$ & $158.5 \pm 5.4$ & 0.75 \\
Maternal weight $(\mathrm{kg})$ & $62.8 \pm 9.3$ & $65.5 \pm 8.8$ & 0.21 \\
Gestational age (days) & $274.9 \pm 6.8$ & $278.0 \pm 7.5$ & 0.08 \\
\hline
\end{tabular}

There was no difference between the groups with regard to the duration of the third stage of labour, blood loss during labour, percentage of women using oxytocin in the second stage of labour, mode of delivery or postpartum length of stay in hospital (table 3). No significant differences were observed in terms of neonatal weight or Apgar scores at 1 or 5 min (table 3 ).

No parturient woman suffered from local anaesthetic systemic toxicity or hip/lower joint pain that needed treatment after the delivery (table 4). Perineal sensation was

Values are presented as mean $\pm \mathrm{SD}$.

PNB, pudendal nerve block. 
Table 2 Primary and secondary outcomes of the second stage of labour

\begin{tabular}{llll}
\hline & $\begin{array}{l}\text { Control group } \\
(\mathbf{n}=36)\end{array}$ & $\begin{array}{l}\text { PNB group } \\
(\mathbf{n = 3 6 )}\end{array}$ & P value \\
\hline $\begin{array}{l}\text { Primary outcome } \\
\quad \text { Second stage of labour (min) }\end{array}$ & $106 \pm 45$ & $73 \pm 31$ & $<0.001$ \\
\hline $\begin{array}{l}\text { Secondary outcomes } \\
\text { Additional injection times }\end{array}$ & $1(1-2)$ & $0(0-1)$ & $<0.001$ \\
\hline Bupivacaine consumption (mg/hour) & $17.35(15.45-21.55)$ & $6.7(6.7-16.23)$ & $<0.001$ \\
\hline DRAM & & & 0.88 \\
\hline DRAM1 (mm) & $3.57 \pm 0.97$ & $3.54 \pm 0.81$ & $<0.001$ \\
\hline DRAM2 (mm) & $1.79 \pm 0.43$ & $3.97 \pm 0.65$ & 0.014 \\
\hline Urge to defecate (\%) & $24(68.6)$ & $33(91.7)$ & 0.002 \\
\hline Maternal cooperation & & & \\
$\quad$ Good (\%) & $7(20.0)$ & $19(52.8)$ & $12(33.3)$ \\
\hline Moderate (\%) & $15(42.9)$ & $5(13.9)$ & 0.004 \\
\hline Poor (\%) & $13(37.1)$ & $33(91.7)$ & \\
\hline Preservation of lower limb motor function (\%) & $22(62.9)$ & & \\
\hline
\end{tabular}

Values are presented as mean $\pm \mathrm{SD}$, median $(\mathrm{IQR})$ or number (\%).

${ }^{*}$ DRAM1 is defined as DRAM before PNB. DRAM2 is defined as DRAM $30 \mathrm{~min}$ after PNB.

DRAM, the difference between contracted and relaxed thicknesses of the rectus abdominis; PNB, pudendal nerve block.

normal in all parturient women when tested at 24 hours (table 4).

\section{DISCUSSION}

This prospective, double-blind, randomised trial demonstrated a shorter duration of the second stage of labour with the application of a bilateral PNB, which was secondary to the reduced need for supplemental dosing of the epidural. Compared with the control group, the need for administration of additional boluses and the total hourly dosing of the epidural anaesthetic during the second stage of labour were lower, and the DRAM2 was greater, in the PNB group. The percentage of women with an urge to defecate was higher in the PNB group, and maternal cooperation and the preservation of lower motor function were better in the PNB group than in the control group.

A meta-analysis by Sharma et $a l^{13}$ determined that epidural analgesia, while providing excellent relief during the first stage of labour, exhibited diminishing effectiveness during the second stage of labour. A retrospective study involving 19259 deliveries reported that

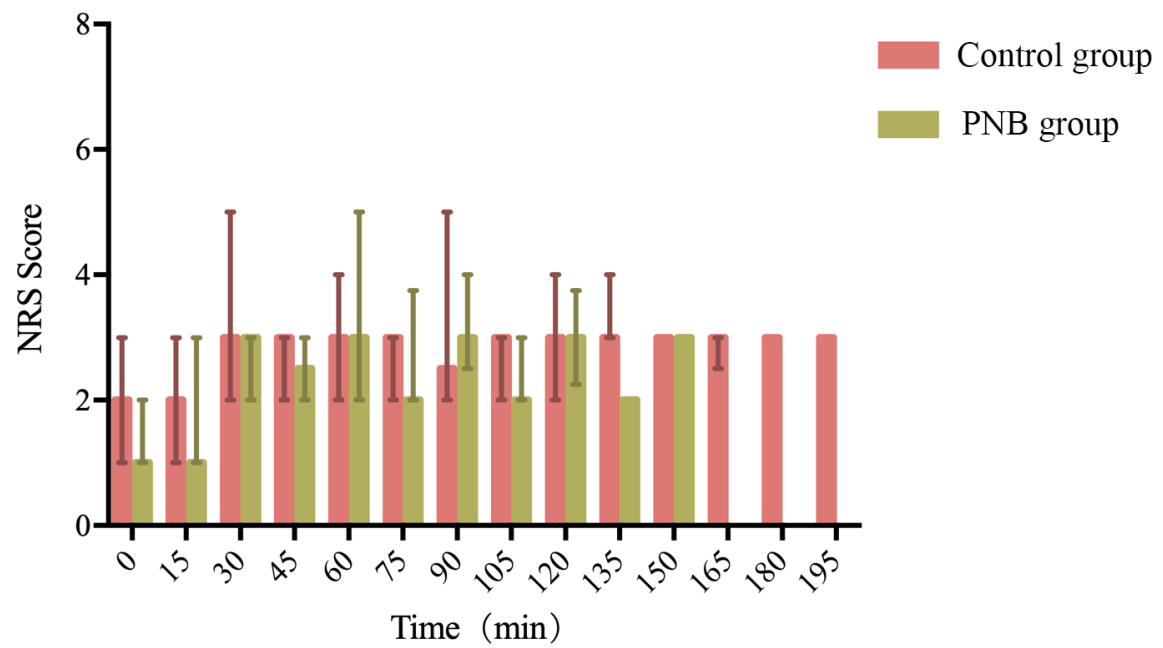

Figure 3 Median (IQR) of NRS scores during the second stage; 0 min represents NRS scores at the beginning of the second stage of labour. Data were compared using $\chi^{2}$ test and there were no significant differences between the two groups from 0 to $105 \mathrm{~min}$. There were four women at $120 \mathrm{~min}$, one woman at 135 and $150 \mathrm{~min}$, and no woman at $165-195 \mathrm{~min}$ in the PNB group. NRS, Numeric Rating Scale for pain; PNB, pudendal nerve block. 
Table 3 Additional data collected

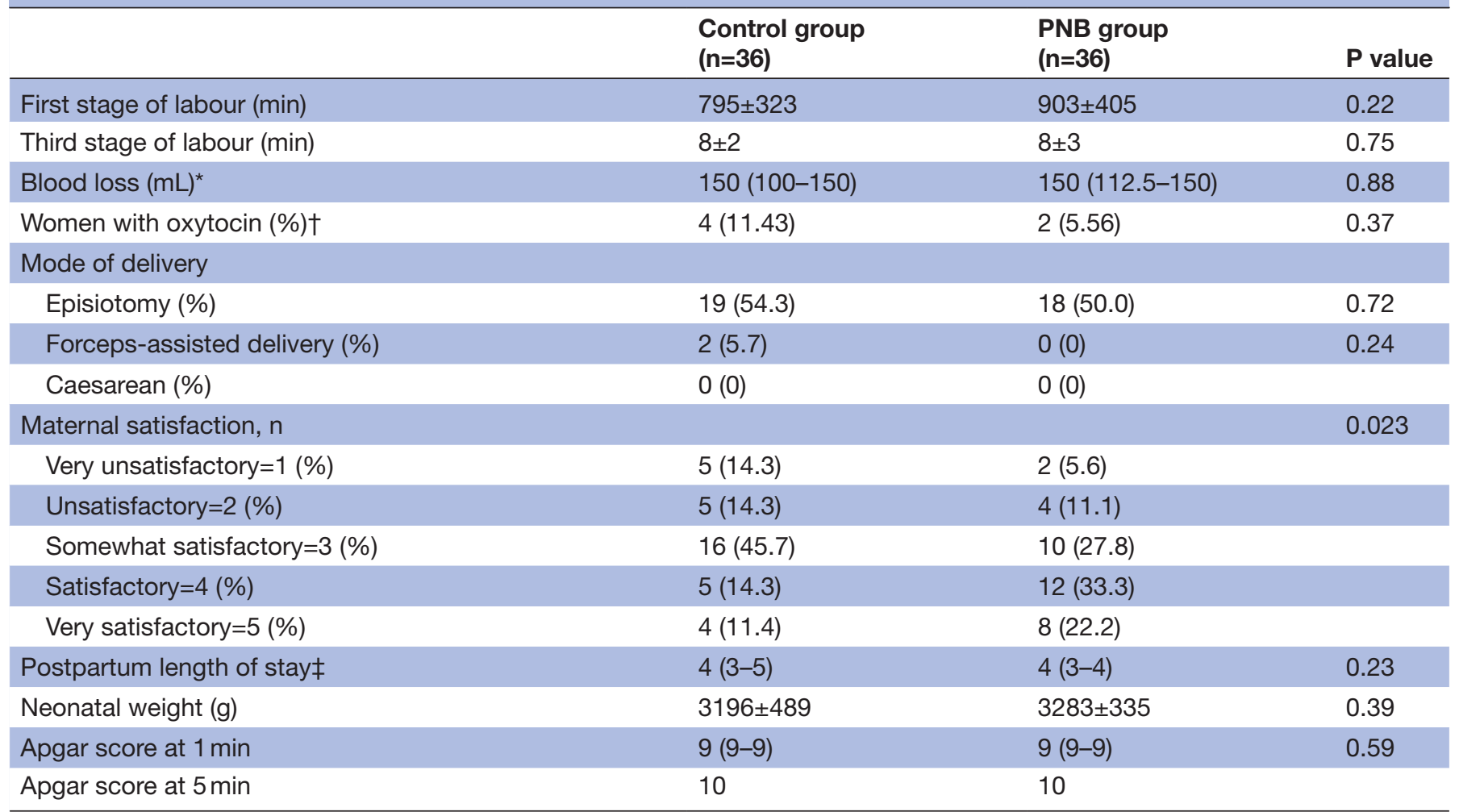

Values are presented as mean $\pm \mathrm{SD}$, median (IQR) or number (\%).

*The approximate amount of the blood lost during labour.

†The number (percentage) of women using oxytocin in the second stage of labour.

$\ddagger$ The duration from the day of labour to the day of discharge.

PNB, pudendal nerve block.

$6.8 \%$ of patients had inadequate analgesia despite initial adequate analgesia (although $98.8 \%$ ultimately received adequate pain relief). ${ }^{14}$ Burn et $a l^{15}$ demonstrated, in a study using radiopaque materials, that anaesthetic solutions injected into the lumbar epidural space tended to spread in a more cephalad manner than in a caudal direction thereby occasionally resulting in insufficient anaesthesia to the sacral nerve roots. On the other hand, labour pain is transmitted through the lower thoracic, lumbar and sacral nerve roots and should be amenable to epidural blockade. ${ }^{16}$ The pain of the first stage of labour is caused by the stretching and distention of the lower

\section{Table 4 Complications of PNB}

\begin{tabular}{lll}
\hline & $\begin{array}{l}\text { Control group } \\
(\mathbf{n}=36)\end{array}$ & $\begin{array}{l}\text { PNB group } \\
(\mathbf{n}=\mathbf{3 6})\end{array}$ \\
\hline Intravascular injection & 0 & 0 \\
Haematoma & 0 & 0 \\
Nerve damage & 0 & 0 \\
Hip/lower joint pain & 0 & 0 \\
Abnormal perineal & 0 & 0 \\
sensation after a day & & \\
\hline
\end{tabular}

Values are presented as number.

PNB, pudendal nerve block. segments of the uterus and cervix. Here, sensory nerve fibres that accompany sympathetic nerve endings travel through the T10-L1 spinal nerves and enter the dorsal horn of the spinal cord. ${ }^{16}$ Labour pain in the second stage is secondary to perineal stretching via the pudendal nerve (sacral roots S2-S4). ${ }^{4}$ These varied and multiple neural pathways and the distribution of anaesthetic solution illustrate why epidural analgesia during the second stage of labour may fail to sustain its effects. Abenhaim and Fraser ${ }^{3}$ demonstrated that the failure to sustain optimal analgesia during the second stage of labour increases the risks of a difficult delivery. Thus, it is common to increase the amount of the analgesic during the second stage of labour to sustain effective pain relief. However, the need to use more local anaesthetic may contribute to an increase in side effects. Lower body muscle weakness resulting from epidural analgesia may inhibit normal fetal rotation and descent and maternal expulsive efforts, particularly when the epidural agent is administered in early labour. ${ }^{6}$

The pudendal nerve arises from sacral spinal nerves S2-S4, and branches into the inferior rectal nerve, perineal nerve and dorsal nerve of the clitoris. The inferior rectal nerve has an abundance of sensory nerve fibres, which makes the perineum extremely sensitive to painful stimuli. There is some evidence the PNB also decreases 
the urge to push and is associated with prolongation of the second stage of labour. ${ }^{17} 18$ However, we disagree. PNB provides a dense analgesia of the birth canal, and contributes to a lower need and therefore a decreased consumption of epidural local anaesthetic during the second stage of labour, thereby mitigating its negative effects.

Although greater dosages of epidural analgesia may ease the pain of the second stage of labour, it hinders the function of the pelvic splanchnic nerves which are crucial for vaginal delivery. ${ }^{9} 19$ The pelvic splanchnic nerves arise from the anterior rami of the sacral spinal nerves S2-S4, with postganglionic fibres located in the distal one-third of the transverse colon, the pelvic organs and the cervix in women. Also, Wilson $e t a l^{20}$ concluded that epidural analgesia significantly increased the risk of postpartum urinary retention. The sensory signals of the rectum are transmitted from the gut to the brain via the 'gut-brain axis.' These signals are transmitted from the peripheral terminals of the extrinsic sensory nerve fibres, and via their axons within the spinal splanchnic and pelvic nerves, to the spinal cord. ${ }^{21}$ With full cervical dilation and the resultant descent of the presenting part, parturient women develop the urge to 'bear down' and the urge to defecate in the second stage of labour. ${ }^{22}$ In our study, a bilateral PNB reduced the need for supplementation of epidural analgesia in the second stage of labour, alleviated the adverse impact to the sacral spinal nerves and preserved the function of the pelvic splanchnic nerves, therein allowing parturient women to keep their sensation of pelvic pressure and the urge to defecate.

After the cervix is dilated fully, the important force in fetal expulsion is produced by maternal intra-abdominal pressure. In a recent study, Qian $e t a l^{23}$ showed that during the first stage of labour contractions are primarily caused by the uterus, while both uterus and abdominal muscles are responsible for contractions during the second stage of labour. The rectus abdominis muscle is controlled by thoracic nerves T7-T12 and plays a vital part in labour. Regional analgesia may reduce the reflexive urge to push and may impair the ability to contract abdominal muscles effectively. ${ }^{24}$ Nydahl et $a l^{25}$ demonstrated that 60 min after epidural injections the electromyography was reduced to $60 \%-63 \%$ at the level of T7. The PNB provides dense analgesia of the birth canal without motor blockage of the rectus abdominis muscles, which are needed to 'push' during the second stage of labour. In our study, the strength of the maternal rectus abdominis muscle in the PNB group was significantly stronger, which is of paramount importance to women during labour.

The performance of an ultrasound-guided bilateral PNB in every maternity patient with epidural labour analgesia is worthy of consideration, especially for women with severe labour pain due to malposition, macrosomia or poor analgesia during the first stage of labour. Performing bilateral PNB in women with epidural analgesia can not only guarantee the safety and effectiveness of labour analgesia, but may also shorten the length of the second stage of labour secondary to the reduced need for supplemental dosing of the epidural and allow a better delivery environment during the labour process (better abdominal contraction, maintain the urge to defecate, better maternal cooperation and so on).

There were three limitations to our study. First, given our strict inclusion criteria, all parturient women enrolled had fetuses in the head-down presentation and had good analgesia during the first stage of labour. It would require further investigation to prove that PNB would show similar results in women who were subject to a difficult delivery. Second, we were unable to assess the spread area of the study solution after administration of the PNB technique because the study was double-blinded. Third, some indicators have not been prespecified in the trial registry and may pose a risk of bias.

\section{CONCLUSION}

In this study, ultrasound-guided bilateral PNB significantly decreased the amount of bupivacaine used and consequently shortened the length of the second stage of labour in nulliparous women with epidural labour analgesia. PNB may serve as an additional effective analgesic strategy during the second stage of labour. Further multiinstitutional studies using larger patient populations will be required to confirm our findings.

\section{Author affiliations}

${ }^{1}$ Department of Obstetrics and Gynecology, Zhejiang University School of Medicine Women's Hospital, Hangzhou, Zhejiang, China

${ }^{2}$ Department of Anesthesiology, The First Affiliated Hospital of Wenzhou Medical University, Wenzhou, Zhejiang, China

${ }^{3}$ Department of Obstetrics and Gynecology, The Second Affiliated Hospital and Yuying Children's Hospital of Wenzhou Medical University, Wenzhou, Zhejiang, China ${ }^{4}$ Department of Anesthesiology, Ohio State University Wexner Medical Center, Columbus, Ohio, USA

Acknowledgements The authors thank the nurses at the Department of Obstetrics, The First Affiliated Hospital, Wenzhou Medical University who were involved in the study and the nulliparous women enrolled.

Contributors JX and RZ were involved in the conception and design, and in the conduct, analysis and writing of the study. WS and SW were involved in the conduct of the study, collected the data and assisted with the revision. YX, TP and XX were involved in data analysis and revised the manuscript. JZ and XX helped conduct the study, data collection, data analysis, manuscript preparation and are responsible for the study design. All authors critically reviewed and revised all drafts and approved and are accountable for the accuracy and integrity of the final version.

Funding The authors have not declared a specific grant for this research from any funding agency in the public, commercial or not-for-profit sectors.

Competing interests None declared.

Patient consent for publication Not required.

Ethics approval Full ethical approval has been granted by the Ethics Committee of The First Affiliated Hospital of Wenzhou Medical University (ethical number: 2016-172).

Provenance and peer review Not commissioned; externally peer reviewed.

Data availability statement Data are available upon reasonable request from the corresponding author.

Open access This is an open access article distributed in accordance with the Creative Commons Attribution Non Commercial (CC BY-NC 4.0) license, which permits others to distribute, remix, adapt, build upon this work non-commercially, and license their derivative works on different terms, provided the original work is 
properly cited, appropriate credit is given, any changes made indicated, and the use is non-commercial. See: http://creativecommons.org/licenses/by-nc/4.0/.

\section{ORCID iD}

Junzhao Zhao http://orcid.org/0000-0002-2385-205X

\section{REFERENCES}

1 Shmueli A, Salman L, Orbach-Zinger S, et al. The impact of epidural analgesia on the duration of the second stage of labor. Birth 2018;45:377-84.

2 Cheng YW, Shaffer BL, Nicholson JM, et al. Second stage of labor and epidural use: a larger effect than previously suggested. Obstet Gynecol 2014;123:527-35.

3 Abenhaim HA, Fraser WD. Impact of pain level on second-stage delivery outcomes among women with epidural analgesia: results from the people study. Am J Obstet Gynecol 2008;199:500.e1-500. e6.

4 Hawkins JL. Epidural analgesia for labor and delivery. N Engl J Med 2010;362:1503-10.

5 Breen TW, Shapiro T, Glass B, et al. Epidural anesthesia for labor in an ambulatory patient. Anesth Analg 1993;77:919???924-24

6 Camann W. Pain relief during labor. N Engl J Med 2005;352:718-20.

7 Anderson D. Pudendal nerve block for vaginal birth. J Midwifery Womens Health 2014;59:651-9.

8 Tafeen $\mathrm{CH}$, Freedman $\mathrm{HL}$, Harris $\mathrm{H}$. Combined continuous paracervical and continuous pudendal nerve block anesthesia in labor. Am J Obstet Gynecol 1968;100:55-62.

9 Burden HW, Price GT, Renegar RH, et al. Effects of peripheral nerve lesions during pregnancy on parturition in rats. Anat Embryol 1990;182:499-501.

10 Hawker GA, Mian S, Kendzerska T, et al. Measures of adult pain: visual analog scale for pain (vas pain), numeric rating scale for pain (NRS pain), McGill pain questionnaire (MPQ), short-form McGill pain questionnaire (SF-MPQ), chronic pain grade scale (CpGs), short Form-36 bodily pain scale (SF. Arthritis Care Res 2011;63:S240-52.

11 Bendtsen TF, Parras T, Moriggl B, et al. Ultrasound-Guided pudendal nerve block at the entrance of the pudendal (Alcock) canal: description of anatomy and clinical technique. Reg Anesth Pain Med 2016;41:140-5.
12 Riddoch G, Bristow WR, Cairns H, et al. Aids to the examination of the peripheral nervous system. Her Majesty's Stationery Office. London: The Medical Research Council, 1976.

13 Sharma SK, McIntire DD, Wiley J, et al. Labor analgesia and cesarean delivery: an individual patient meta-analysis of nulliparous women. Anesthesiology 2004;100:142-8.

14 Pan PH, Bogard TD, Owen MD. Incidence and characteristics of failures in obstetric neuraxial analgesia and anesthesia: a retrospective analysis of 19,259 deliveries. Int J Obstet Anesth 2004;13:227-33.

15 Burn JM, Guyer PB, Langdon L. The spread of solutions injected into the epidural space. A study using epidurograms in patients with the lumbosciatic syndrome. Br J Anaesth 1973;45:338-45.

16 Eltzschig HK, Lieberman ES, Camann WR. Regional anesthesia and analgesia for labor and delivery. N Engl J Med 2003;348:319-32.

17 Langhoff-Roos J, Lindmark G. Analgesia and maternal side effects of pudendal block at delivery. A comparison of three local anesthetics. Acta Obstet Gynecol Scand 1985;64:269-73.

18 Zador G, Lindmark G, Nilsson BA. Pudendal block in normal vaginal deliveries. clinical efficacy, lidocaine concentrations in maternal and foetal blood, foetal and maternal acid-base values and influence on uterine activity. Acta Obstet Gynecol Scand Suppl 1974;53:51-64.

19 Higuchi T, Uchide K, Honda K, et al. Pelvic neurectomy abolishes the fetus-expulsion reflex and induces dystocia in the rat. Exp Neurol 1987;96:443-55.

20 Wilson MJA, Macarthur C, Shennan A, et al. Urinary catheterization in labour with high-dose vs mobile epidural analgesia: a randomized controlled trial. Br J Anaesth 2009;102:97-103.

21 Brierley SM, Hibberd TJ, Spencer NJ. Spinal afferent innervation of the colon and rectum. Front Cell Neurosci 2018;12:467.

22 Gary Cunningham KJL, Steven L, Bloom DJS, et al. Williams obstetrics. 955. 25th ed. McGraw-Hill Education, 2018.

23 Qian X, Li P, Shi S-Q, et al. Simultaneous recording and analysis of uterine and abdominal muscle electromyographic activity in nulliparous women during labor. Reprod Sci 2017;24:471-7.

24 Gary Cunningham KJL, Steven L, Bloom DJS, et al. Williams obstetrics. 976. 25th ed. McGraw-Hill Education, 2018.

25 Nydahl PA, Axelsson K, Philipson L, et al. Motor blockade and EMG recordings in epidural anaesthesia. A comparison between mepivacaine $2 \%$, bupivacaine $0.5 \%$ and etidocaine $1.5 \%$. Acta Anaesthesiol Scand 1989;33:597-604. 